\title{
INSTILLING INDEPENDENCE THROUGH STRUCTURED ENVIRONMENT AMONG INTELLECTUALLY CHALLENGED CHILDREN
}

\author{
Farah Iqbal \\ Professor \\ Department of Psychology, University of Karachi, \\ Sindh, Pakistan \\ Email: fiqbal@uok.edu.pk
}

\author{
Aen-ul-Huda \\ Research Scholar \\ Department of Psychology, University of Karachi, \\ Sindh, Pakistan \\ Email: aenulhuda@live.com
}

\begin{abstract}
Intellectually challenged children needs lot of effort to put things together and builds meaning in order to operate well in the environment. Low cognitive abilities becomes restrictive and thus develops either dependency on the care giver or negative behaviors among children. The current study aims to evaluate the fact that whether an effective structured teaching method, based on the components of TEACCH programme for Autism Spectrum Disorder can bring the same sense of independence and positive behaviors, as with children with other intellectually challenged children or not. For this a sample of 23 intellectually challenged children with different intellectual level and diagnoses other than ASD were evaluated on few standard structured components based on TEACCH methodology, on tasks which they have already mastered when presented in practice area i.e. independent work station. The present study indicates that previously students were becoming prompt dependent but after the introduction of structured teaching, they can function well independently. Some other aspects were also being noticed which can open areas of further research.
\end{abstract}

\section{KEYWORDS}

Structured teaching, intellectually challenged children, independent work behaviour

\section{INTRODUCTION}

According to the Convention on the Rights of Persons with Disabilities (CRPD), the global agreement which makes sure that people with disabilities and people without disabilities are treated equally and in Pakistan's Article 5 reserves the right with equality and non-discrimination of persons with disabilities, and empathize on putting the person first then condition. (Government of Pakistan, 2013). Intellectually Challenged is an alternative term formerly known as Mental Retardation, as per widespread definition called Intellectual Difficulty or Special Needs, refers to the significantly subnormal cognitive functioning and is measured by an IQ of around 70 or less along with a delay in age-appropriate adaptive behaviours such as social, communication, life skills etc. appeared prior the age of 18 years (American Psychiatric Association, 2000). This includes diagnostic criteria as per DSM V of Down Syndrome, Cerebral Palsy, Global 
PJER, Vol 4, Issue 2 (2021) Instilling independence through ... developmental delay etc. Due to cognitive deficiencies children with intellectual challenges, faces difficulties in most of the higher learning processes and these individuals learn differently and as it's hard for them to understand, retrieve or condense their skills, and hence they feel less motivated to learn difficult or new tasks. Reviewing traditional researches by Baker et al. (2015), the graduates who are not much intellectually able within classrooms, achieve high of life in varied parts of routine whilst a suitable assistance. When an initial Parental interview for assessments are made, the only parental concern evolves around one query "When my child is been able to live on his own independently?" This is the strongest concern of any parent with child with intellectual challenges.

The educational program and instructional strategies for such students ought to be adjusted to assist them with accomplishing their potential in both academic and useful everyday issues like daily living skills, communication skills and social skills etc. Therefore many such instructional and educational strategies has been successfully proposed so far and the research on betterment in these areas is still in progress to make them more effective day by day. Instructional and educational strategy is major basic variables for improvement. It improves people's understanding of themselves and the world. It improves an individual's sense of self-fulfillment and prompts vast social benefits to people and society. Instruction raises persons' efficiency, imagination and vocational progresses also. A complete target of guidance-based strategy is to support an individual become dependable, autonomous, and contributing individual from the community to which the individual has a standing. For children with unique instructive requirements, the educational training is meant to boost their latent capacity and assist them with getting a changed individual. Training in these areas to such children, gives freedoms to obtaining information and capacities that improve individual autonomy and socially appropriate behavior within the society.

One of such fruitful academic models is the implementation of 'structural teaching ' which has been prominent in academic settings worldwide and has quickly gotten one of the vital means of teaching tool in Autism Spectrum training. It has been contemplated while working with kids on Spectrum that, visual appealing tasks that depend more continuing with eye-hand coordination, or motor-instilled or spatial capacities are better understood and enjoyed the most by kids with Autism Spectrum. While still addressing the flaws, there is a strong possibility to build on these assets. As a result, if the activities, including those that are verbally and consistent, are organized for kids in such a way that both what is anticipated and how to accomplish it are obvious from the start, the child will be more likely to succeed (Schopler et al, 1998).

As the dependence for proof-based practice has expanded, proofs for research have developed to question the adequacy of organized teaching segments. The research evidences from the past literature reviews recommend that organized way of teaching has constructive outcomes upon challenging practices and furthermore builds commitment and task organizations which remain independent (Marie Howley 2015). Encouraging free interactions and execution of classroom exercises and diminishing reliance on others, is a significant target when showing youngsters with inabilities (Hall, McClannahan, \& Krantz, 1995; Mechling \& Gast, 1997). TEACCH (Treatment and Education of Autistic and related Communication-handicapped CHildren) is a clinical assistance and expert preparing program, located at the University of North Carolina, 
PJER, Vol 4, Issue 2 (2021)

Instilling independence through ... which has consolidated preparing program, located at the University of North Carolina, which has consolidated and added to the proof base of knowledge in interventions of autism. The program was begun in 1972 by the late Dr. Eric Schopler and presently stretched to nine territorial places for North Carolina that offer clinical types of assistance to individuals with Autism Spectrum of every age bracket. The TEACCH methodology is named "Structured Teaching" which is predicated on the proof and perception that people with Autism share as an example of neuropsychological challenges and qualities that we call the culture of Autism (Mesibov et al. 2005), which includes the following 8 components:

1. Comparative strong point and inclination for handling visual data (contrasted with troubles with processing the audio listening ability, especially of language). Straightforward facts and descriptions are grasped better. Kids on Autism Spectrum usually don't get that, words' importance may change as per the circumstance where they are being utilized. Therefore, it is hard for them to comprehend sarcastic statements, humor, jokes and criticism in an indirect form. Moreover, the message in idioms and proverbs is also a difficult thing for them to understand. They focus and understand more as a literal meaning.

2. Increase in consideration regarding sequencing however trouble with sequencing, coordinating, interfacing, or getting importance from them. Equally Consistency involves similar skills and for that reason, it is uncommon for such children to perform in an illogical manner. Since kids with Autism Spectrum experience difficulty in coordinating data, as they have poor skills needed in organizations. It is hard for them to grasp on the quick comprehension about the ideal outcome. (Mesibov \& Shea, 2004). They tried to learn the compound tasks comprising multiple steps but at the same time they do not understand the underlying meaning and correlation of all the steps involved in that task that leads to the end result.

3. There is lots of disparity in attention (personalities are often very distractible sometimes, furthermore, at different occasions strongly engaged, with challenges moving consideration effectively). Focusing and maintaining attention to a task is difficult for kids on Autism Spectrum. Similarly, the challenge is to know what to watch out for and to divert attention from one stimulus to another. This is especially problematic when there is a rapid and diverse social exchange (Simpson, et al., 2008). Distraction is additionally brought about by the powerlessness to incorporate sensory data. The kid may focus towards the teacher's watch, not to what she is showing a flashcard; or may divert his or her attention from the task to a sound that is so mellow that the members in the classroom does not even hear it. Sometimes the involuntary need for self-stimulatory behavior also causes distraction in these children. Regardless of the cause of diversion, youngsters experience issues deciding the significance of outer stimuli or inner requirements during the time spent for carrying out some task.

4. Correspondence issues, which fluctuate by development level, however consistently incorporate disabilities within the starting or social utilization of language (pragmatics). The theoretical words are incredibly ordering on the grounds that it's anything but identified with something intangible that can be seen or called for. In absence of explicit visual interactions with things or exercises, words are practically difficult to comprehend. Processing the language includes taking the speaking sounds that they hear 
PJER, Vol 4, Issue 2 (2021)

Instilling independence through ...

and transforming them into examples of directions. Youngsters with open language troubles in language processing may not be attentive when somebody educates them and/or on occasion will most likely be unable to adhere to long directions. At the point when given some task to finish, they may fail to remember what they have been approached to do or will actually want to finish a couple of steps only. A few scientists have recognized normal consideration and the utilization of images as key breaks in language and correspondence for kids with Autism Spectrum (Sigman \& Ruskin, 1999).

5. Difficulty in regards to time duration or time sequence. They may look restless during exercises too excessively that wants to finish task very quickly or may be too lazy. They might have issues perceiving the beginning or completion of an activity, furthermore they find difficulty in calculating the time sequence that what would be the duration of the exercise and when will it get completed.

6. There is chance or trend has been set and it became routines and therefore it needs some precautions, to perform that activities. Incompletion of a tedious activity can lead to trouble and nervousness. Research shows that insisting on performing activities in a certain way can be an attempt by the child to follow certain predicted sequence of activities and set own rules contained from the environment. (Baron Cohen, 2002). It is believed that once a sequence is registered, it must be continued with consistency. In this manner, building up a predictable schedule guarantees that nothing can change.

The proven information shows that the predictable schedule turns out to be more prevailing and complex when an individual faces changes by either from people around in day to day existence, activities, accommodation, or when they are going through distressful times. Anxiety has several factors it may due to fear that does not allow to socialize and whether they can make mistakes and do not know if there will be a modification in routine, circumstance or any other expectations. Children can oppose change by complaining or dismissing their conduct, by becoming violent or disobedient. They may be irritated and upset. If there are unexpected changes can lead towards congestion or meltdown experience. As the child grows, he or she may learn to tolerate changes but may not overcome this behaviour.

7. Exceptionally serious interests and motivations to interface in preferred exercises and troubles separating once locked in. This is again the factor associated with distractibility as mentioned earlier. These type of involuntary needs may lead to distractible behaviours that hinders focus on primary task importance.

8. Marked sensory preferences and aversions. The processing of sensory elements is the way in which our sensory system acknowledges and comprehends the essence of sensations (Miller, 2000). Kids with autism have extreme reactions to sensory stimulation. They can become very touchy (overly sensitive) in senses, or even the opposite, that is, hyposensitive (insufficiently sensitive). Hypersensitive kids are overwhelmed by even moderate degrees of sensation and work towards blockage from where sensory data like light, sound and contact is input; and these are normally not a sensitive input for a typical individual. In contrast, hyposensitive children are not motivated by sufficiently normal sensory inputs and usually seek additional stimulation. TEACCH by and large suggests four sorts of design. The first of them is the physical framework which is termed as the actual format or rounds around an individual's current 
PJER, Vol 4, Issue 2 (2021)

Instilling independence through ...

environment, like bedroom, playroom, classroom, and so on. For instance:

a. Utilizing components like the arrangement of furniture or visual signals that direct a student about exercises to happen in particular places and where to stand or sit inside the space, and

b. Diminishing the environment related interruptions or overstimulation via seating a student who is faced far from an entrance or window.

The second sort of design includes coordinating and imparting the grouping of events of the day by making this organization (for example a timetable) comprehendible and significant to the student. The timetable is a significant part of organized learning. These are visual signs that tells children what is going to happen throughout the day. They illustrates the list of activities that would be performed during the day. The most essential kind of plan utilizes objects to help the researcher make the change towards resulting movement (e.g., real hand towel to be used for bathing; small plate to be utilized for snacking). For all the more strongly developed, and progressed students, pictures or composed words are utilized for timetables, and individual plans are of expanded length (e.g., part-day, entire day, week by week plan).

The next structure is the visual structure which refers to visual assimilation of activities which builds and clarify instructions concerning the tasks. At the point when an assignment is introduced in clear visual structure it is simpler for the kids to recognize its highlights. Since visual data is tangible and non-threatening, the kids get familiar with the assignment without any problem. Essentially, visual organization likewise works with data handling. Assignment directions can be coordinated to such an extent that sensory processing related overload can be avoided. Visual directions are realistic portrayal of assigned steps. Visual directions are likewise useful in disclosing the day by day schedule to the youngsters. The final very design is connecting single assignments into a grouping of exercises, called the work/action system, to expand the amount of the time that the individual is definitively occupied with during those useful exercises. Physical design and timetables permit kids with Autism Spectrum to realize where to go and what's in for the day, hence work frameworks instruct them in certain fruitful activities. Work plans and systems are fundamental for preparing individuals for being trained in development regarding work ethics and behaviours. Through work frameworks, youngsters know the conduct that is anticipated from them in work exercises.

Systems support to organize and perform tasks. Work systems can be classified into four types of information i.e. (1) What he or she is alleged to perform, (2) For how much time the activity will prevail until it ends and what is the percentage of repetitions individual will do, (3) What does he think of the progress that the individual in question is gaining ground toward finishing the task and how the person can see that the action is done ? (4) What he will do afterwards?

An exquisite recent study demonstrated the viability of work/action frameworks (joining different components of design too) found inside the investigation by Hume et al (2007). The investigation, was planned with three people with Autism Spectrum, with age ranging from six, seven and twenty years, reported about striking increments, contrasted with standard degrees, of on-task conduct and noticeable decrement of educator inciting when organized individual work frameworks dependent on TEACCH 
standards were carried out. Also, Hume (2009) archived inclination of on-task behaviour and precision, decline in other's help or support and assignment finishing duration, and transitioning to other situations when work frameworks were introduced to 3 seven year-old kids utilizing the plan of participants given multiple probes.

The current research aims to study the impact of work systems, physical structure and visual cues on behavior of children with children diagnosed with special needs (like Down's syndrome, Intellectual Disability, Cerebral Palsy etc.). Though this programme is devised for ASD children and has already been practiced and has shown remarkable improvements with the behaviours, it was aimed towards evaluating the impact of structured environment on independence for kids with other neurodevelopmental disabilities as well.

\section{RESEARCH OBJECTIVE}

1. Do Intellectually Challenged children excluding Autism Spectrum Disorder (ASD) will also show on task behavior accuracy when provided with STRUCTURED system? 2. Do Intellectually Challenged children excluding Autism Spectrum Disorder (ASD) will become less prompt dependent when provided with STRUCTURED system?

\section{RESEARCH QUESTIONS}

1. Intellectually Challenged Children excluding Autism Spectrum Disorder (ASD) will also show on task behavior accuracy after implementation of structured system. 2. Intellectually Challenged Children excluding Autism Spectrum Disorder (ASD) will be less prompt dependent after implementation of structured system.

\section{RESEARCH METHODOLOGY}

Initially, 25 special needs children (ages 04-15 years old) were selected but 2 children were excluded from the data as they left school after the baseline recording. So 23 intellectually challenged children through convenience sampling method from a special school, were included for this purpose of study. All varying in diagnostics like; Cerebral Palsy, Down Syndrome, Intellectual challenged (Not otherwise specified-NOS) and ranging in intellectual level from mild to moderate level of intelligence.

First a checklist of behaviors (attached in Appendix) were derived from TEACCH structured system through TEACCH Fidelity Proforma (Kilham et al, 2009) in order to record the baseline of current level of functioning of children under observation in TEACCH based induction programme. The responses were recorded in YES/NO. The domain A of the checklist is about physical structure of the task/activity which includes the understanding where to find things/activities and where they belong, Domain B includes structure through visual means, Domain C includes structure of work station or independent work area and last domain $\mathrm{D}$ is about measurement of positive behaviours in result of structuring the task / work system including prompt dependency.

Then the components of structured teaching based on TEACCH system was introduced after the formal training of teachers of the classes involved. The checklist was reevaluated after 3 months of induction of the programme. The behaviours were recorded and analyzed via Descriptive Statistical analysis. 


\section{FINDINGS \& RESULTS}

The sample includes 15 male and 8 female students from the age range of 04 years to 15 years. Out of 23 individuals the diagnostic division includes, 09 children were with Down syndrome, 09 children with Cerebral Palsy and 05 children with Intellectual deficiency (Not otherwise specified). The sample includes 12 children with mild intellectual abilities and 11 with moderate level of intellectual abilities. The results of the current study shows that there is a difference of scores in comparison to their recording before implementation of the structured program. The table 1 and Graph 1, shows the mean scores value of 4 domains of the structured program before and after implementation.

\section{Graph 1: Bar Graph showing Comparisons of Mean Scores among 4 domains of structure system before and after implementation}

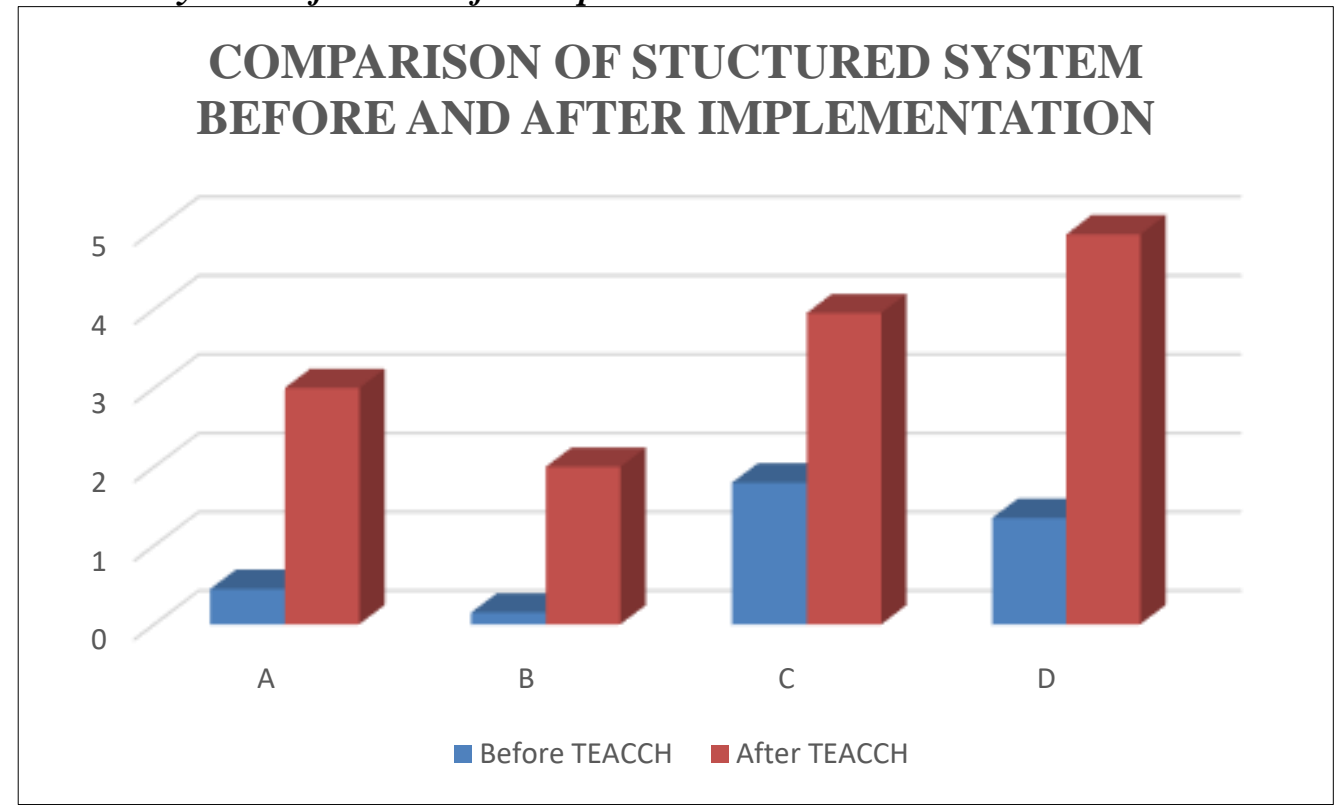

It was noticed that mean scores of skills / behaviours recorded were low as compared to the behaviours recorded after 3 months of implementation of program. The mean scores in the domain of physical structure of the environment which includes 3 behaviours to understand the physical structure of the classroom. Only $15 \%$ of the understanding was there among children for the physical structure of the environment before the implementation but after 3 months the children are able to understand $100 \%$. The understanding through visual structuring was only $7 \%$ before implementation and after that all the children are able to understand the visual instructions i.e. $100 \%$. For mastered task practicing area, children used to be prompt dependent and doing $45 \%$ of the tasks independently and now they are doing at $98 \%$ of the time independently (See Graph 4). As far as the confidence level and sense of responsibility and motivation to work is concerned children were functioning $27 \%$ at this level before the structured methodology but now $99 \%$ children has acquired these positive behaviours (See table 2 and Graph 2). The overall baseline data of behavior and structured methodology shows a significant rise in graph (see Graph 3) which depicts that the on task behaviors were about the average range of expectation i.e. $60 \%$ of the behaviors were well managed with the previous mode of instructions and after implementation the graph rises to $100 \%$ 
approximately.

Table 1: Table showing Mean scores on each domain before and after TEACCH implementation

\begin{tabular}{cccc}
\hline & $\begin{array}{c}\text { Before } \\
\text { TEACCH }\end{array}$ & $\begin{array}{c}\text { After } \\
\text { TEACCH }\end{array}$ & $\begin{array}{c}\text { Total items in each } \\
\text { domain }\end{array}$ \\
\hline $\begin{array}{c}\text { A } \\
\text { (Phys. }\end{array}$ & 0.45 & 3 & 3 \\
$\begin{array}{c}\text { Structure) } \\
\text { B }\end{array}$ & 0.15 & 2 & 2 \\
$\begin{array}{c}\text { (Visual means) } \\
\text { C } \\
\text { (Work system) } \\
\begin{array}{c}\text { D } \\
\text { (Behaviours) }\end{array}\end{array}$ & 1.8 & 3.95 & 4 \\
$N=25 \quad$ & 1.35 & 4.95 & 5 \\
\hline
\end{tabular}

Graph 2: Graph showing difference of scores before and after TEACCH implementation across 4 domains

\begin{tabular}{|c|}
$\begin{array}{l}\text { Percentage of scores before and } \\
\text { after teacch implementation } \\
\text { across } 4 \text { domains } \\
\text { Before TEACCH }\end{array}$ \\
\begin{tabular}{|c|c|c|c|}
\hline $100 \%$ & After TEACCH \\
$15 \%$ & $7 \%$ & $45 \%$ & $99 \%$ \\
\hline 1 & 2 & 3 & 4 \\
\hline
\end{tabular} \\
\hline
\end{tabular}

Table 2: Table showing percentages of acquired behaviours before and after implementation of TEACCH programme.

\begin{tabular}{ccc}
\hline & $\begin{array}{c}\text { Percentage } \\
\text { \% after TEACCH }\end{array}$ & $\begin{array}{c}\text { Percentage } \\
\text { \% after TEACCH }\end{array}$ \\
\hline A & $15 \%$ & $100 \%$
\end{tabular}

(Phys. Structure)
B
$07 \%$
$100 \%$

(Visual means)

C

$45 \%$

$98 \%$

(Work system)
D
$27 \%$
$99 \%$

$N=25$ 


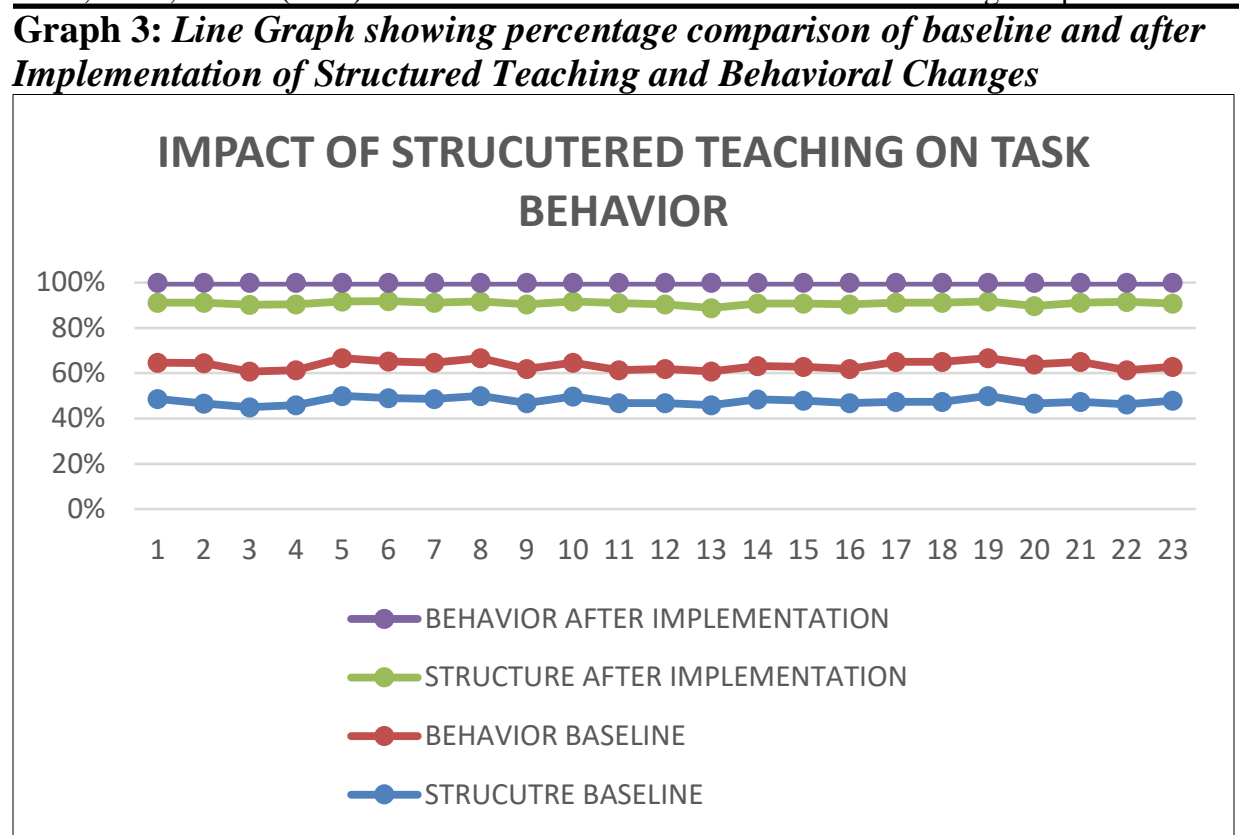

Graph 4: Prompt Dependency Comparison

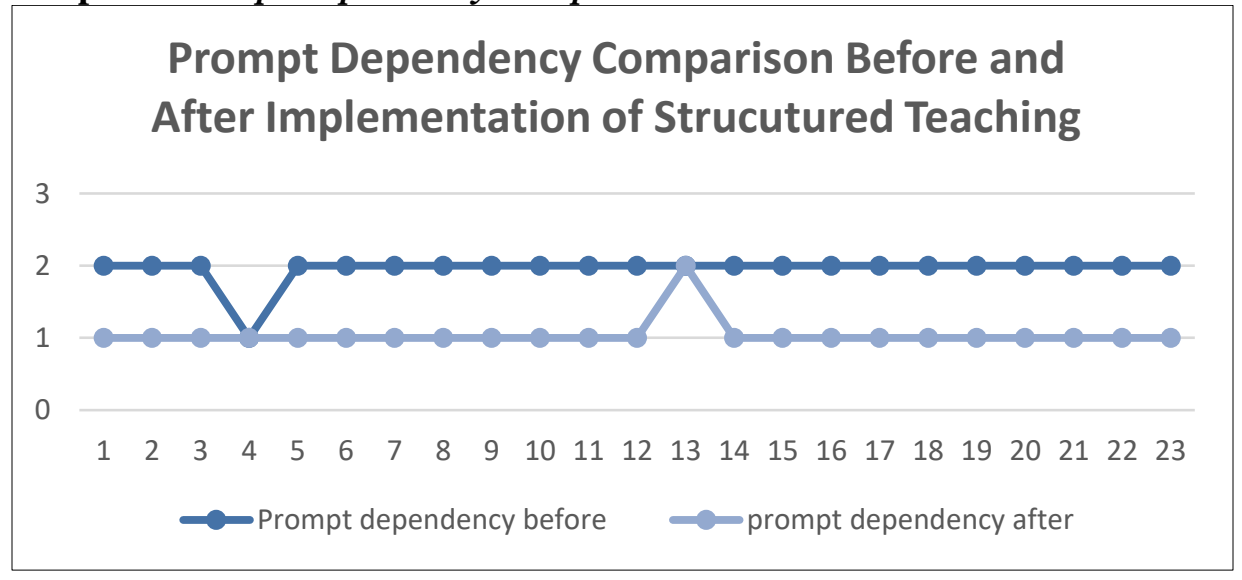

\section{DISCUSSION}

It has been noticed that the primarily fathers of neurodevelopmental child among both parents, usually found in constant worry about the powerlessness to gain proficiency with a vocation and become a self-governing mature, as stated by Etten (1980). These children shows more reliant on the family that sometimes led families to pleading for financial assistance. Person centered approach believes in developing qualities and interests, instead of underlining the deficits as a whole including the family or carer. One of the most positive side of children with special needs is that they understand the simple, visually sound tasks. To make these individuals more independent and the ability to control their own behavior while the execution of tasks, has been a continued apprehension for children with special needs. Creating an opportunity for performance abilities, positive motivation to perform and adequate performance style, are few training objectives set for students with limitations in instructive abilities and needs. The difficulty starting work on their own, keep working and looking for a new activity 
when a certain task is done, these are few behaviors that children while working on task does not persist without the supervision. There must be effective environment of classroom for these kids to give an organization that assists education and forms of teaching, and facilitates the acquisition of language, public and pedagogical skills, and behavioral management. The academic oriented strategies that give design and security to the instructive interaction, empower these individuals to expect the necessities and assumptions for the assignment, and teach a variety of skills in the areas of concern that are supportive for these children (Earles Vollrath, T.L., Cook, K. T., Robbins, L., and Ben-Arieh, J. 2008). One way to deal with exhibiting the adequacy of an extensive program like TEACCH as a structured teaching model, is observational help for the parts and components (ASHA, 2006). Organized Teaching proposes four fundamental systems, even though more refined analysis is required on the grounds that the individual influences of those instruments and their sub-segments haven't been contemplated but pragmatic evidences are available for few of them. The necessary tools of Structured Teaching are (a) organizing the area and tasks in a way which makes sense to the child; (b) in order to support children with weak skills by using their visual learning strengths and interests; (c) using interests as their premium learning pattern and engage through this medium; and (d) in order to support meaningful communication make use of self-directed instruction.

Here in the present study the components of study were mainly physical and visual structure of environment, especially within the work systems and positive behaviors that manifest confident personality among children with intellectual challenges. Though few researches tries to demonstrate the efficacy of work systems through TEACCH system, an effective demonstration show of the viability of work/action frameworks (consolidating different components of construction also) is found in the investigation by Hume and Odom (2007). Schopler et al. (1995) suggested planning assignments in a straightforwardly clear way. Such that, educators give students ASD with guidelines in regard to the abilities needed to finish a job, how much the student needs to do to do the job, and a visual portrayal of what result is related with an individual. Hence, students with ASD can perform assignments without direct guidance from others, thereby, advancing independence that they will be in need of for working at adult positions (TEACCH, 1996).

The components of Structured Teaching depends emphatically on utilizing visual data to advance commitment in useful exercises and to decrease the disarray and trouble that can be caused when an excessive amount of processing of language is required. Visual representation is a vital component of actual design, plans, directions for exercises, correspondence, and updates about assumptions and cutoff points. This visual information is passed on in different manner, relying upon the higher thinking skills of the child that may vary from tangible or symbolic items for early learners at very early age levels or with very low intellectual abilities. And can be presented into written format like a to-do list and reminder strips for advance learners with better cognitive abilities (Mesibov et al. 2005). During this study the effective work systems were visually presented with the visual instructions in the form of pictures, so that the child has an idea and understands the expectedness that what needs to be done. It was noticed here, that children which were not previously doing well on task that were already mastered and need teachers' prompt and without any visual support. These visual support were helpful as the children started to work independently because of better 
PJER, Vol 4, Issue 2 (2021)

Instilling independence through ... understanding of the sequence of work system made easier visually. Stimuli that has visual representations, works with the children to handle information more capably (Lal, 2010). Hume et al. (2012) who report extensive accuracy in task fulfillment of language and educational domains. This investigation gives some proof that utilization of a work system reduces the need for adult prompts whilst improving the accuracy of task completion. Sometimes, failure to understand the task steps or failure to understand the verbal instruction or distraction due to any other external stimuli, results in frustration, anxiety of the child with intellectual difficulty. This eventually leaves the child with behavior issues. While structuring the given instruction by visual means reduces these confusions, minimizes the anxiety and therefore leaves no behavioral issues as an outcome.

Another research development on the effectiveness of Structured Methodology based on TEACCH, reports that at 18 months after admission, some serious adverse conducts were significantly lower for the TEACCH program group than the others, and the families of those in the TEACCH program were significantly more satisfied than those in other homes. (Van Bourgondien et al. 2003). This study was conducted with the families of 6 adults with autism entered a residential program based on the TEACCH model. They studied the relation between satisfaction of the family, clients' abilities and their challenging conducts. They compared the factors for 26 similar adults who had also applied for the TEACCH program but with a delay.

Similarly, in Welterlin's (2009) thesis, utilizing randomly decided or picked task to treatment or waiting list control conditions, assessed the adequacy of a 12-meeting mediation that trained TEACCH strategies to guardians of 10 two-and three-year old youngsters with Autism Spectrum. Treatment brought about huge expansions in fine engine abilities, diminished maladaptive conduct, and expanded freedom, quantifiable expansions in visual open abilities, improved parental showing abilities, and checked declines in parental pain. Even in the present study, with special children it was noticed that they acquired behaviours like sense of responsibility, motivation to work more and more and sense of accomplishment when they independently finishes the task. Behaviour therapists believe that behaviors that are positively appreciated are likely to persist. Children with typical development are usually motivated to work because of the social approval they can get from others in the form of praise and appreciation, the internal satisfaction of the task they perform, and the sense of accomplishment when the task is done well. Children with Autism Spectrum ought not to be propelled by any of them. Notwithstanding, there are substantial things and exercises that inspire these youngsters. Those who are providing training to these children, must determine what interests their child the most. For instance some children like edibles, books, sensory toys etc. Hence, these should be readily available as per child's preference so that the child can be praised and reinforced immediately when he or she performs the task correctly. The reinforcement should be given immediately as soon as the child emits a correct response otherwise it loses its efficacy. It is also equally important for the teacher how he or she manages to transition the social praise or tangible rewards into the activities or tasks becomes reinforcing for the child and feels satisfied and motivated after their completion. This is what the structured teaching strategy is building for the children and therefore considered a powerful tool for instilling self-motivation and fading out all tangible rewards. Burgess and Gutstein (2007) endorse that self-reliance, confidence, control of decision, freedom and independence are 'predictors of well- 
PJER, Vol 4, Issue 2 (2021)

Instilling independence through ...

being' and as such ought to be remembered for quality of life pointers for individuals with Autism Spectrum. As structured instructional teaching expects to advance freedom and confidence, it very well may be contended that the exploration data demonstrates positive outcomes comparable to these concepts, for instance indicating that the methodology increments both independent decision making (Watanabe 2003) and task completion. In an examination led by the Greek Society for the Protection of Autistic People, Siaperas and Beadle-Brown (2006) report the results, where in 12 adults with Autism, residing in a home were shown utilizing the organized tutoring approach. After the half year intercession period the subjects showed huge improvement in close to personal freedom, social capacities, and communication capacities. Kusmeirski and Henckel (2002) decided the adequacy of TEACCH program on decrease of maladaptive conduct and upgrade of freedom in practical sessions. Four youngsters with Autism Spectrum, of 8 to 13 years, dwelling in a private home were considered. Standard information was gathered for 30 days followed by 30 days of mediation to two kids. Results demonstrated that utilization of TEACCH plan diminished maladaptive conduct in one kid, while the other kid enhanced the capacity to complete assignments completely yet independently. The difference in baseline and intervention scores in the current study clearly indicates the positive impact of intervention of structured environment and instructions on the behavior of children while on task independence among children with intellectual challenges. These further enhance the positive behaviors of children together with motivation, confidence and interest to do more and more.

\section{CONCLUSION}

TEACCH systems have likewise been adjusted for early intervention programs; residence-based projects; social gathering groups, summer camping, and other programs for recreation; individual and gathering directing meetings; clinical, dental, and treatment and therapy settings, and dental and protected business sites. Also, in current study it was adapted for children with special needs other than Autism Spectrum diagnosis. It absolutely would have had the experience of seeing loose agreement and utilization of the ideas and methods among the individuals who endeavor to utilize them. But the clinical strength of Structured Teaching even in defective conditions has been striking. Organized Teaching standards and procedures are being used universally in classrooms, summer camping programs, and residence-based projects. TEACCH personnel have likewise been welcome to instruct in additional 20 nations in Europe, South America, Africa, and the Middle East, and Structured Teaching systems have been effectively and impressively executed in every single enormous city (e.g., London, Tokyo, Hong Kong) and rustic spaces of India, Pakistan, Brazil, and different nations (Schopler 2000). The limitations observed in current study is the small sample size.

\section{RECOMMENDATIONS}

This study certainly opens room for more comprehensive and clearer findings with larger sample data and therefore unlocks further quantitative research analysis. Some studies also evaluate the positives of the TEACCH program and role in a family. Hungelmann (2001) liked a home program in which guardians of children with Autism Spectrum were encouraged how to execute the organized self-teaching. The study includes initial meetings, cure sessions, home appointments and follow-up sessions. The score showed that the children showed enormous progress in mastering the tasks during the progression with the help of TEACCH program. There is participation of elders that 
PJER, Vol 4, Issue 2 (2021)

Instilling independence through ...

saw the program as a viable method of correcting their child's deficit. The results of the current study may also contribute towards the usefulness at home for parents who are needing proof based and appropriate intercession for kids with intellectual challenges especially over the concern to make them function independently.

\section{REFERENCES}

American Speech-Language-Hearing Association. (2006). Guidelines for speech-language pathologists in diagnosis, assessment, and treatment of autism spectrum disorders across the life span. [http://www.asha.org/members/deskref-journal/deskref/default].

Baker JN, Rivera CJ, Morgan JJ, Reese N (2015). Teaching algebraic equations to middle school students with intellectual disabilities. J. Am. Acad. Spec. Educ. Professionals, pp. 2943.

Bohart, A. C., O’Hara, M., \& Leitner, L. M. (1998). Empirically violated treatments:

Disenfranchisement of humanistic and other psychotherapies. Psychotherapy Research, $8,141-157$.

Burgess, A. \& Gutstein, S. (2007) 'Quality of life for people with autism: raising the standard for evaluating successful outcomes.' Child and Adolescent Mental Health, 12 (2), pp. $80-6$.

Chorpita, B. F. (2003). The frontier of evidence-based practice. In A. E. Kazdin \& J. R. Weisz (Eds.), Evidence-based psychotherapies for children and adolescents (pp. 42-59). New York: Guilford.

Earles-Vollrath, T.L., Cook, K. T., Robbins, L., and Ben-Arieh, J. (2008). Instructional strategies to facilitate successful Learning outcomes for students with autism spectrum disorders. In Educating children and youth with autism: strategies for effective practice. (2nd edition) Simpson, R. L, Smith Myles, B. (Eds.) pp 93-178 Pro Ed. ISBN -13: 978-14164-0210-7. Texas (2008)

Etten, P. (1993). The severely and profoundly handicapped. programme, methods and materials. London: The Mosby Company.

Government of Pakistan (2013). CRPD, State report on implementation of the Convention on the Rights of Persons with Disabilities.

Retrieved online: https://www.ecoi.net/en/document/2027978.html

Hume, K., \& Odom, S. (2007). Effects of an individual work system on the independent functioning of students with autism. Journal of Autism and Developmental Disorders, 37(6), 1166-1180.

Hume, K., Plavnick, J. \& Odom, S. (2012) 'Promoting task accuracy and independence in students with autism across educational setting through the use of individual work systems.' Journal of Autism and Developmental Disorders, 42 (10), pp. 2084-99.

Iovannone, R., Dunlap, G., Huber, H., \& Kincaid, D. (2003). Effective educational practices for students with autism spectrum disorders. Focus on Autism and Other Developmental Disabilities, 18, 150-165.

Kilham, Williams and Costley (2009). An independent outcome study of a TEACCH intervention for children with autism. Aspect TEACCH Pilot Final Report, p 45.

Retrieved online: https://www.yumpu.com/en/document/view/37805160/aspectteacch-pilot-final-report-web/6

Lal, R. (2010). Effect of alternative and augmentative communication on language and social behavior of children with autism. Educational Research and Reviews 5(3)119-125 ISSN 1990-3839

Marie Howley (2015). Outcomes of structured teaching for children on the autism spectrum: does the research evidence neglect the bigger picture? Journal of Research in Special Educational Needs · Volume $15 \cdot$ Number $2 \cdot 2015$ 106-119. 
PJER, Vol 4, Issue 2 (2021)

Instilling independence through ...

Mesibov, G. B., Shea, V., \& Schopler, E. (with Adams, L., Burgess, S., Chapman, S. M., Merkler, E., Mosconi, M., Tanner, C., \& Van Bourgondien, M. E.). (2005). The TEACCH approach to autism spectrum disorders. New York: Springer.

Mesibov, G.B., Shea, V., and Schople, E. (2004). The TEACCH Approach to Autism Spectrum Disorders. Springer, ISBN 978-0-306-48646-3, New York.

Miller, L. L. S. (2000). Toward a consensus in terminology in sensory integration theory and practice: part 1: taxonomy of neurophysiological processes. Sensory Integration Special Interest Section Quarterly, 23 (1), 1-4.

Schopler, E. (Ed.). (2000). International priorities for developing autism services via the TEACCH model [Special issue]. International Journal of Mental Health, 29.

Schopler, E, Mesobov, G.B., \& Kunce, L. J. (Eds.). (1998). Asperger's Syndrome or High Functioning Autism? Plenum Press, ISBN 0-306-45746-6 New York

Schopler, E., Mesibov, G. B., \& Hearsey, K. (1995). Structured teaching in the TEACCH

system. In E. Schopler \& G. B. Mesibov (Eds.), Learning and cognition in autism (pp. 243-

267). New York: Plenum. Chapter that describes components of structured teaching, according to the TEACCH model.

Sigman M, Ruskin E (1999). Continuity and change in the social competence of children with Autism, Down syndrome, and developmental delays. Monographs of the Society for Research in Child Development 64 (1): v-114 ISSN: 1540-5834

Simpson, R. L, Smith Myles, B. (Eds.) (2008) Educating children and youth with autism: Strategies for effective practice. (2nd edition) Pro Ed. ISBN -13: 978-1-4164-0210-7. Texas.

TEACCH. (1996). visually structured tasks: Independent activities for students with autism and other visual learners. Chapel Hill, NC: Division TEACCH.

Van Bourgondien, M. E., Reichle, N. C., \& Schopler, E. (2003). Effects of a model treatment approach on adults with autism. Journal of Autism and Developmental Disorders, 33, 131-140.

Watanabe, M. \& Sturmey, P. (2003) 'The effect of choice-making opportunities during activity schedules on task engagement.' Journal of Autism and Developmental Disorders, 33 (5), pp. 535-8.

Welterlin, A. (2009). The Home TEACCHing Program: A study of the efficacy of a parent training early intervention model. Unpublished doctoral dissertation, Rutgers University. 